\title{
Control-Oriented Mathematical Modeling of Humidity in PEM Fuel Cells
}

\author{
Ahmad Haddad ${ }^{1}$, Louay Elsoufi ${ }^{2}$, Marc Mannah ${ }^{1}$ and Hasan Bazzi ${ }^{1}$ \\ 1. School of Engineering, Department of Electrical Engineering, Lebanese International University, Beirut, Lebanon \\ 2. School of Engineering, Department of Mechanical Engineering, Lebanese University, Tripoli, Lebanon
}

\begin{abstract}
Fuel cell technology is a promising renewable energy for a wide range of applications. Among various types, the PEM (Proton Exchange Membrane) fuel cell is the most attractive for its clean products and high power density. However, controlling its humidity is one of the most challenging problems. This is due to the interdependence of several phenomena contributing in membrane's water content. Placing a humidity sensor is unfeasible since the membrane is extremely thin and the sensor will block gas diffusion. This work develops a control-oriented mathematical model that calculates the membrane's water content according to gas humidification rates at the input. The study takes into consideration interactions between charge and mass transport along cell's components. Effects of gas humidification rates on electrical outputs are simulated. Simulations show interesting results regarding efficiency improvement through humidity control.
\end{abstract}

Key words: PEM fuel cell, mathematical modeling, nonlinear systems, membrane's humidity, dynamic power demand.

\section{Notations}

$A$
$a_{\mathrm{w}}$
$C$
$C_{d l}$
$C_{g e o m}$
$D$
$E$
$F$
$i$
$j$
$j_{o}$
$j_{t}$
$J$
$L$
$P$
$R$
$R$
$T$
$V$
$X$

\section{Greek-letters}

$\alpha$

$\eta$

\author{
Area $\left(\mathrm{m}^{2}\right)$ \\ Water activity \\ Concentration $\left(\mathrm{mol} / \mathrm{m}^{3}\right)$ \\ Double Layer capacitance $(F)$ \\ Geometrical capacitance $(F)$ \\ Diffusion coefficient $\left(\mathrm{m}^{2} / \mathrm{s}\right)$ \\ Nernst voltage $(V)$ \\ Farafay constant $(\mathrm{C} / \mathrm{mol})$ \\ Current $(A)$ \\ Current density $\left(A / \mathrm{cm}^{2}\right)$ \\ Exchang current density $\left(A / \mathrm{cm}^{2}\right)$ \\ Limit current density $\left(A / \mathrm{cm}^{2}\right)$ \\ Gas diffusion flux $(\mathrm{mol} / \mathrm{s})$ \\ Thickness $(m)$ \\ Pressure $(\mathrm{Pa})$ \\ Resistance $(\Omega)$ \\ Gas constant $(\mathrm{J} /$ mole. $K)$ \\ Temperature $(K)$ \\ Voltage (Volt) \\ Mole fraction
}

Charge transfer coefficient

Voltage loss (Volt)

Corresponding author: Ahmad Haddad, assistant professor, research fields: control systems and renewable energy.
Water content

$\begin{array}{ll}\text { Subscripts } & \\ a, a n & \text { Anode } \\ a c t & \text { Activation } \\ b d & \text { Back diffusion } \\ c, c a & \text { Cathode } \\ c o n c & \text { Concentration } \\ e & \text { Electrode } \\ \mathrm{H}^{+} & \text {Hydrogen protons } \\ \mathrm{H}_{2} & \text { Hydrogen } \\ \mathrm{H}_{2} \mathrm{O} & \text { Water } \\ \text { in } & \text { Input } \\ \mathrm{M}, m & \text { Membrane } \\ \mathrm{o} & \text { Ohmic } \\ \text { out } & \text { Output } \\ \mathrm{O}_{2} & \text { Oxygen } \\ t & \text { Total }\end{array}$

Superscripts

$\begin{array}{ll}B P & \text { Bipolar plate zone } \\ s a t & \text { Saturation } \\ T C & \text { Triple contact zone }\end{array}$

\section{Introduction}

Fuel cell technology faces many obstacles retarding its marketing such as production cost and lifetime limitation. Among real obstacles is the control of 
physical phenomena occurring inside the cell in high dynamics of power demand. Particularly, controlling internal humidity of fuel cells is one of the most challenging problems. In fact, several interdependent phenomena contribute in membrane's water content. Placing a humidity sensor is unfeasible since the membrane is extremely thin and the sensor will block gas diffusion. Hence, a control-oriented mathematical modeling of water transport is needed to improve fuel cell's efficiency and lifetime.

Strong dependence and coupling between internal phenomena are the main cause of mathematical modeling limitation in literature. To avoid complexity, most of works focus on studying each phenomenon separately from the others. The existing models could be classified into three main categories:

(1) Static models describing the fuel cell's polarization curve [1-8]. These models are suitable for stationary applications where the operating point does not change rapidly. However, when it comes to dynamic applications these models are not convenient since they cannot follow the rapid change in power demand.

(2) Dynamic linear models such as state space linear models [9-12]. They result from the linearization of nonlinear models around an operating point. Being simple and easy to control are their main advantages. However, these works do not describe precisely highly nonlinear phenomena occurring inside the fuel cell. Results in Ref. [13] show a considerable error between linear models and experimental tests. Therefore, the fuel cell's control in dynamic applications cannot rely on this type of models.

(3) Dynamic nonlinear models that focus on studying each phenomenon separately from the others. For example in the works of Refs. [14, 15] electrochemical modeling was not coupled with mass balance modeling. Furthermore, they do not consider the effect of temperature and humidity variations on the output voltage and voltage losses. Other works are based on fuzzy logic and artificial neural networks approaches to model the fuel cell [16-23]. Based on learning techniques, these computational models are not appropriate for fuel cells because they are not deterministic: they are black box; that is internal phenomena are not described. Moreover, model's learning requires time which is not convenient for controlling a critical parameter such as membrane's humidity.

Important works dealing with modeling membrane's water content in transient behaviors are the ones given by Refs. [24, 25]. In their works, Wang Y. and Wang C. studied the water distribution with respect to the space scale in a three-dimensional model as well as the two-phase flow. Fuller and Newman [26] examined experimentally the water transport number in Nafion 117 membrane and presented the relationship between transport number and electro-osmotic coefficient. Okada et al. [27] modeled the water transport and concentration profile at the anode side.

In summary, the above models do not consider all parameters influencing the membrane's humidity, such as: water mole fractions in hydrogen and oxygen, water production at the cathode as well as the phenomena of diffusion and electro-osmosis between anode and cathode. Furthermore, they do not study the dynamic evolution of the humidity and its influence on the fuel cell's efficiency.

This work develops a control-oriented mathematical model of the water transport inside PEM (proton exchange membrane) fuel cells. The proposed model considers all parameters affecting the membrane's humidity including gas humidification rates. Effect of humidity on electrical outputs is also studied. The model takes into account interactions between charge and mass transport along the fuel cell's components.

\section{PEM Fuel Cell Principle}

PEM fuel cell uses pure hydrogen and oxygen as 
reactants and produces electricity and clean water. At the anode side, the hydrogen molecule is split into protons and electrons. Protons permeate across the electrolyte (membrane) to the cathode while electrons flow through an external circuit and produce electric power. Oxygen, usually in the form of air, is supplied to the cathode and combines with electrons and hydrogen protons to produce water. The chemical reaction governing this principle is:

$$
\mathrm{H}_{2}+\frac{1}{2} \mathrm{O}_{2} \rightarrow \mathrm{H}_{2} \mathrm{O}+2 e^{-}+\text {heat } \text {. }
$$

At normal conditions of pressure and temperature, the electrochemical potential resulting from chemical reactions is given by Nernst equation [28]:

$$
E=E^{0}+\frac{R_{g} T}{2 F} \operatorname{In}\left(\frac{P_{\mathrm{H}_{2}} \sqrt{P_{\mathrm{O}_{2}}}}{P_{\mathrm{H}_{2} \mathrm{O}}}\right)
$$

where $E^{0}=1.23 \mathrm{~V}$ is the reversible cell potential and $E$ is the open circuit voltage. When the fuel cell is loaded, $E$ is reduced due to ohmic, activation and concentration losses $\left(\eta_{0}, \eta_{\text {act }}\right.$ and $\left.\eta_{\text {conc }}\right)$ :

$$
\begin{aligned}
& \eta_{0}=R_{0} j \\
& \eta_{a c t}=\frac{R_{g} T}{\alpha 2 F} \operatorname{In}\left(\frac{j}{j_{0}}\right) ; \\
& \eta_{\text {conc }}=\frac{R_{g} T}{\alpha 2 F} \operatorname{In}\left(1-\frac{j}{j_{0}}\right) .
\end{aligned}
$$

According to Eq. (1), two moles of hydrogen need one mole of oxygen to produce one mole of water and four electrons. Consequently, the relation between current density $j$ and gases diffusion flux $J$ is shown in Ref. [18]:

$$
j=2 F J_{H_{2}}^{T C}=2 F J_{H_{2} O}^{T C}=4 F J_{O_{2}}^{T C}
$$

\section{Single Cell Modeling}

Mathematical modeling is a fundamental tool for fuel cells investigation and development. It permits to describe and control different phenomena interacting inside the single cell. In a fuel cell, there are various processes such as gas diffusion, charge transfer and water transport that occur in coupling with electrochemical reactions. This paper deals with dynamic nonlinear modeling of the PEM fuel cell using the semi-physical approach. The advantage of this approach is to provide mathematical modeling for internal physical phenomena using an analog representation. The objective is to model the fuel cell's diffusional and electrical process using an electrical equivalent circuit. Diffusion principle is used to model gas concentrations and to establish relationships between internal and external gas pressures and gas diffusion flows. Water transport is used to describe the fuel cell's internal humidity and to calculate the membranes water content according to gas humidification rates at the input. Electrical principles are used to describe the evolution of electrical outputs as voltage, current and powers. Finally, the global model is elaborated by combining diffusional, water transport and electrical approaches in one equivalent circuit. The fuel cell's dynamics are represented by non-linear differential equations in the state-space form. The state-space representation exhibits great advantages in systems analysis and control. Besides, it presents a powerful tool for simulation.

The main assumptions of the model are stated as follows:

(1) The model deals with a single PEM cell. Indeed, having a planar geometry, the PEM fuel cell stack is built by piling up multiple single cells. Hence, electrical, charge and mass transport phenomena remain valid for the stack because in a serial connection the single cell voltage is added up.

(2) The model considers a one-dimensional diffusion inside cell's components (in the $x$ direction). This assumption is not restrictive due to gas pressure difference between anode and cathode and since the layers of the electrodes are very thin.

(3) The temperature is considered constant and uniformly distributed inside the cell's components. 
However, the study of temperature variation and distribution in the space scale requires a thermal study which is not the subject of this work.

Given these assumptions, we define in Table 1 the input/output variables of the model. We consider as inputs the hydrogen diffusion flow $\left(J_{\mathrm{H}_{2}}^{A}\right)$, water mole fractions in hydrogen $\left(X_{\mathrm{H}_{2} \mathrm{O}}^{A}\right)$ and oxygen $\left(X_{\mathrm{H}_{2} \mathrm{O}}^{\mathrm{C}}\right)$ as well as gas pressures $\left(P_{\mathrm{H}_{2}}^{B P}, P_{\mathrm{O}_{2}}^{B P}, P_{\mathrm{H}_{2} \mathrm{O}}^{\mathrm{BP}}\right)$ at the bipolar plates zone (BP). At outputs we consider the cell's output voltage $\left(V_{\text {out }}\right)$ and current density $(j)$.

\subsection{Diffusional Process}

In this part the diffusion principle is used to establish expressions for internal gas pressures $P^{T C}$ and diffusion flows $J^{T C}$ with respect to external ones $P^{B P}$ and $J^{B P}$ (Fig. 1).

In a planar geometry model (PEM fuel cell) with cross-flow circulation of gases, the diffusion flow caused by the concentration difference between BP and TC zones is given by Fick's first law:

$$
J=-D \nabla C
$$

where $J$ is the diffusion flow, $D$ is the gas diffusion coefficient and $\nabla C$ is the concentration gradient. The low diffusion layer thickness and the porous characteristic of the electrodes permit to assume that gases diffuse in one dimension (in the $x$ direction, see Fig. 1). Therefore, the expression of the diffusion flow given in Eq. (5) becomes:

$$
J=-D \frac{\partial C}{\partial x}
$$

Table 1 Input/output variables.

\begin{tabular}{|l|l|}
\hline Inputs & Description \\
\hline$u_{1}: J_{H_{2}}^{B P}$ & Hydrogen diffusion flow \\
\hline$u_{2}: X_{H_{2} O}^{A}$ & Water mole fraction in hydrogen \\
\hline$u_{3}: X_{H_{2} O}^{C}$ & Water mole fraction in oxygen \\
\hline$u_{4}: P_{H_{2}}^{B P}$ & Hydrogen pressure at the BP zone \\
\hline$u_{5}: P_{O_{2}}^{B P}$ & Oxygen pressure at the BP zone \\
\hline$u_{6}: P_{H_{2} O}^{B P}$ & Water pressure at the BP zone \\
\hline Outputs & Description \\
\hline$y_{1}: V_{o u t}$ & Output voltage \\
\hline$y_{2}: j$ & Current density \\
\hline
\end{tabular}

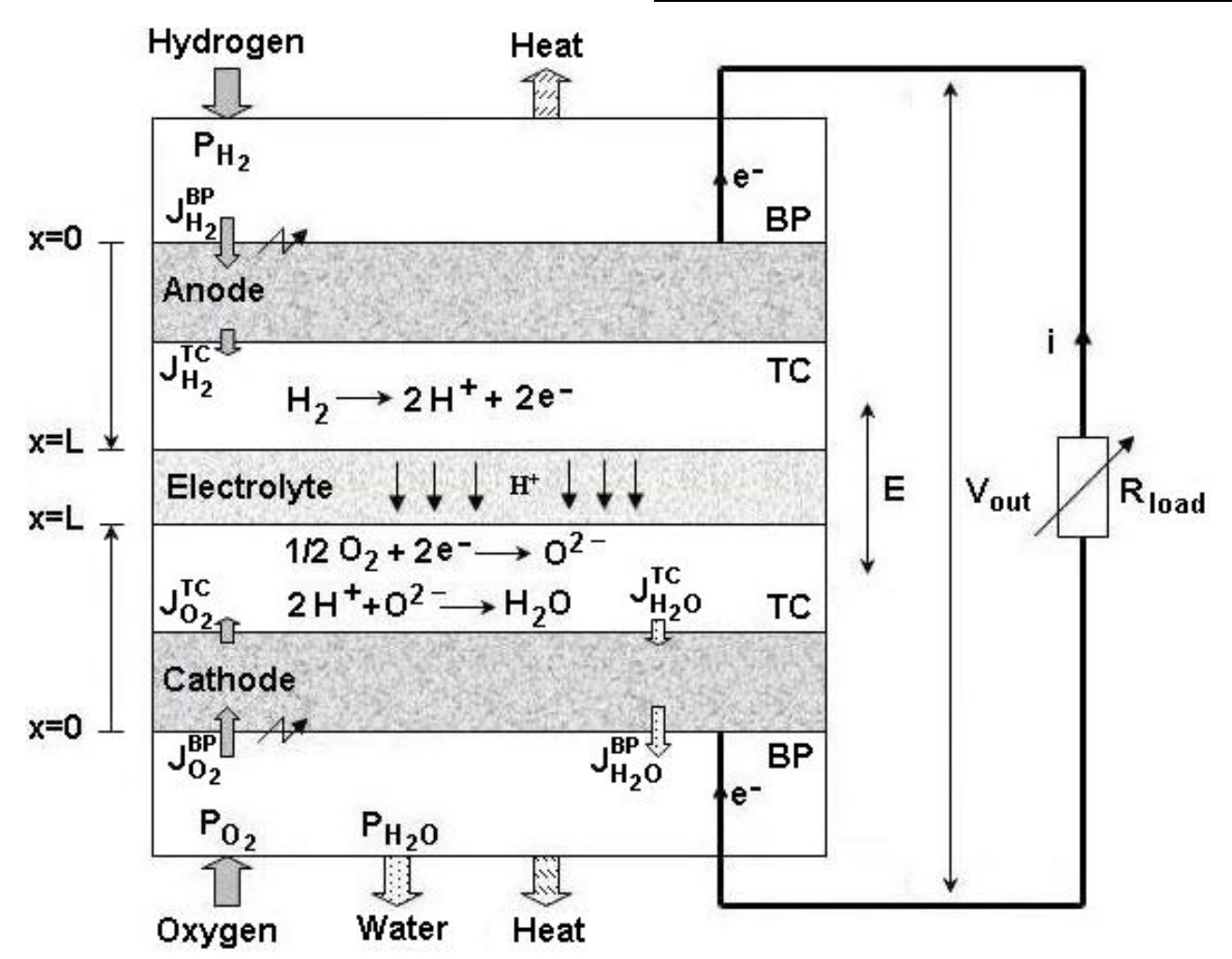

Fig. 1 Gas diffusion through cell components. 
To compute $J$ we use Fick's second law which provides the concentration variation with respect to time:

$$
\frac{\partial C}{\partial t}=D \frac{\partial^{2} C}{\partial x^{2}}
$$

It should be noted that the temporal solution of Eq. (7) is related to the erf function. Since, this latter does not have a continuous solution we use the Laplace transforms to resolve this problem. Laplace transform appears to be more suitable for state-space representation. Indeed, the Laplace transforms of Eq. (7) is given by:

$$
s C(x, s)-C(x, 0)=D \frac{\partial^{2} C(x, s)}{\partial x^{2}}
$$

Since $C(x, 0)=0$, Eq. (8) becomes:

$$
\frac{\partial^{2} C(x, s)}{\partial x^{2}}-\frac{s}{D} C(x, s)=0
$$

The solution of Eq. (9) with the boundary conditions $\quad J^{B P}(s)=-\left.A D \frac{\partial C(x, s)}{\partial x}\right|_{x=0}$ and $C^{T C}(s)=C(L, s)$ is:

$$
\begin{gathered}
C(x, s)=\frac{J^{B P}\left(\exp \left[-\sqrt{\frac{s}{D}}(x-2 L)\right]-\exp \left[\sqrt{\frac{s}{D}} x\right]\right)}{A D \sqrt{\frac{s}{D}}\left[1+\exp \left(2 L \sqrt{\frac{s}{D}}\right)\right]} \\
+\frac{C^{T C}\left(\exp \left[\sqrt{\frac{s}{D}}(x+L)\right]+\exp \left[-\sqrt{\frac{s}{D}}(x-L)\right]\right)}{\left[1+\exp \left(2 L \sqrt{\frac{s}{D}}\right)\right]}
\end{gathered}
$$

Hence, the gas concentration at the BP zone $(x=0)$ is:

$$
C^{B P}(s)=\frac{J^{B P}(s) \tanh \left(L \sqrt{\frac{s}{D}}\right)}{A D \sqrt{\frac{s}{D}}}+\frac{2 C^{T C}(s) \exp \left(L \sqrt{\frac{s}{D}}\right)}{1+\exp \left(2 L \sqrt{\frac{s}{D}}\right)}
$$

At normal conditions of pressure and temperature, gases can be assumed to be ideal. Then, Avogadro's law implies $P^{B P}(s)=R_{g} T C^{B P}(s) \quad$ and $P^{T C}(s)=R_{g} T C^{T C}(s)$.
Then, we have:

$$
\begin{aligned}
& P^{B P}(s)= \\
& \frac{J^{B P}(s) R_{g} T \tanh \left(L \sqrt{\frac{s}{D}}\right)}{A D \sqrt{\frac{s}{D}}}+\frac{2 P^{T C}(s) \exp \left(L \sqrt{\frac{s}{D}}\right)}{1+\exp \left(2 L \sqrt{\frac{s}{D}}\right)}
\end{aligned}
$$

The Taylor first order developments of tanh and $\exp$ functions around zero ( $L$ is very thin) give:

$$
P^{T C}=P^{B P}-\frac{R_{g} T L}{A D} J^{B P}
$$

Now, Eq. (10) with the boundary condition $J^{T C}(s)=-\left.A D \frac{\partial C(x, s)}{\partial x}\right|_{x=L}$ imply:

$$
\frac{2 J^{B P}(s) \exp \left(L \sqrt{\frac{s}{D}}\right)-C^{T C}(s) A D \sqrt{\frac{s}{D}}\left[\exp \left(2 L \sqrt{\frac{s}{D}}\right)-1\right]}{1+\exp \left(2 L \sqrt{\frac{s}{D}}\right)}
$$

The Taylor first order development of exp function around zero and the inverse Laplace transform give:

$$
j^{T C}=j^{B P}-\frac{D}{L^{2}} J^{B P}+\frac{D}{L^{2}} J^{T C}+\frac{A D}{L} \dot{C}^{T C}
$$

In addition, according to Avogadro's law, we have:

$$
j^{T C}=j^{B P}-\frac{D}{L^{2}} J^{B P}+\frac{D}{L^{2}} J^{T C}+\frac{A D \dot{P}^{T C}}{R_{g} T L}
$$

This and Eq. (13) imply:

$$
j^{T C}=\frac{A D \dot{P}^{B P}}{R_{g} T L}-\frac{D}{L^{2}} J^{B P}+\frac{D}{L^{2}} J^{T C}
$$

Given that $J_{H_{2}}^{B P}=2 J_{O_{2}}^{B P}=J_{H_{2} \mathrm{O}}^{B P}$ according to Eq. (4), it follows that

(1) For the hydrogen:

$$
\begin{aligned}
& P_{H_{2}}^{T C}=P_{H_{2}}^{B P}-\alpha_{3} J_{H_{2}}^{B P} ; \\
& j_{H_{2}}^{T C}=\alpha_{1} \dot{P}_{H_{2}}^{B P}-\alpha_{2} J_{H_{2}}^{B P}+\alpha_{2} J_{H_{2}}^{T C}
\end{aligned}
$$

where, $\alpha_{1}=\frac{A D_{H_{2}}}{R_{g} T L}, \alpha_{2}=\frac{D_{H_{2}}}{L^{2}}, \alpha_{3}=\frac{R_{g} T L}{A D_{H_{2}}}$.

(2) For the oxygen: 


$$
\begin{aligned}
& P_{O_{2}}^{T C}=P_{O_{2}}^{B P}-\beta_{4} J_{H_{2}}^{B P} ; \\
& j_{O_{2}}^{T C}=\beta_{1} \dot{P}_{O_{2}}^{B P}-\beta_{2} J_{H_{2}}^{B P}+\beta_{3} J_{O_{2}}^{T C}
\end{aligned}
$$

where, $\beta_{1}=\frac{A D_{O_{2}}}{R_{g} T L}, \beta_{2}=\frac{\beta_{3}}{2}=\frac{D_{O_{2}}}{2 L^{2}}, \beta_{4}=\frac{1}{2 \beta_{1}}$.

(3) For the water:

$$
\begin{aligned}
& P_{H_{2} \mathrm{O}}^{T C}=P_{\mathrm{H}_{2} \mathrm{O}}^{B P}-\gamma_{3} J_{H_{2}}^{B P} ; \\
& j_{\mathrm{H}_{2} \mathrm{O}}^{T C}=\gamma_{1} \dot{P}_{\mathrm{H}_{2} \mathrm{O}}^{B P}-\gamma_{2} J_{\mathrm{H}_{2}}^{B P}+\gamma_{2} J_{H_{2} \mathrm{O}}^{T C}
\end{aligned}
$$

where, $\gamma_{1}=\frac{A D_{H_{2} \mathrm{O}}}{R_{g} T L}, \gamma_{2}=\frac{D_{\mathrm{H}_{2} \mathrm{O}}}{L^{2}}, \gamma_{3}=\frac{R_{g} T L}{A D_{\mathrm{H}_{2} \mathrm{O}}}$.

\subsection{Water Transport}

In this part, we study the water transport through cell components (Fig. 2) in order to state relations between water mole fractions in hydrogen and oxygen, anode and cathode water activities, as well as membrane humidity.

Fig. 2 shows the transport of reactants $\left(\mathrm{H}_{2}, \mathrm{O}_{2}\right)$ and products $\left(\mathrm{H}^{+}, \mathrm{H}_{2} \mathrm{O}\right)$ in the x direction through cell components: bipolar plates (zone BP), anode (zone A), cathode (zone C), catalyst layers (zones TC) and membrane (zone $\mathrm{M}$ ). The input gases $\left(J_{H_{2}, \text { in }}, J_{O_{2}, \text { in }}\right)$ are humidified with water vapor ( $J_{\mathrm{H}_{2} \mathrm{O} \text {,in }}^{\mathrm{A}}, J_{\mathrm{H}_{2} \mathrm{O} \text {, in }}^{\mathrm{C}}$ ). While circulating inside the distribution channels, a part of hydrogen, oxygen and water vapor $\left(J_{\mathrm{H}_{2}}^{A}, J_{\mathrm{O}_{2}}^{\mathrm{C}}, J_{\mathrm{H}_{2} \mathrm{O}}^{\mathrm{A}}, J_{\mathrm{H}_{2} \mathrm{O}}^{\mathrm{C}}\right)$ migrates through diffusion layers (zones $A$ and $C$ ). The other part ( $\left.J_{H_{2}, \text { out }}, J_{\mathrm{O}_{2}, \text { out }}, J_{\mathrm{H}_{2} \mathrm{O}, \text { out }}^{A}, J_{\mathrm{H}_{2} \mathrm{O} \text {,out }}^{C}\right)$ is recirculated outside the cell. Water vapors $J_{\mathrm{H}_{2} \mathrm{O}}^{\mathrm{A}}$ and $J_{\mathrm{H}_{2} \mathrm{O}}^{\mathrm{C}}$ diffuse through the membrane similarly to protons $J_{H^{+}}^{M}$ produced at the anode catalyst layer (zone TC). However, water produced at the cathode catalyst layer (zone TC) $J_{\mathrm{H}_{2} \mathrm{O}}^{T C}$ is decomposed to two parts: The first combines with $J_{\mathrm{H}_{2} \mathrm{O}}^{\mathrm{C}}$ and diffuses through the membrane, the second part is evacuated outside the cell. Hence, the membrane is affected by two phenomena: the electro-osmotic drag represented by the diffusion flow $J_{\mathrm{H}_{2} \mathrm{O} \text {,drag }}$ and the back diffusion flow $J_{H_{2} O, b d}$. The resulting water diffusion flow inside the membrane is $J_{\mathrm{H}_{2} \mathrm{O}}^{\mathrm{M}}=J_{\mathrm{H}_{2} \mathrm{O} \text {, drag }}-J_{\mathrm{H}_{2} \mathrm{O}, \text { bd }}$.

First, we emphasis that water transport is mainly imposed by the mechanisms transport in the membrane. Indeed, resistive effects of species transport inside the cell are much more important in electrolyte (diffusion of a liquid phase) than in electrodes (diffusion of a gas phase). In this context, characterization of transport phenomena in the electrolyte is very important because membrane humidity affects its electrical performances and therefore those of the cell. Hence, the membrane behavior depends on its water content $\lambda$ which is related to anode and cathode water activities $\left(a_{w}^{A}\right.$ and

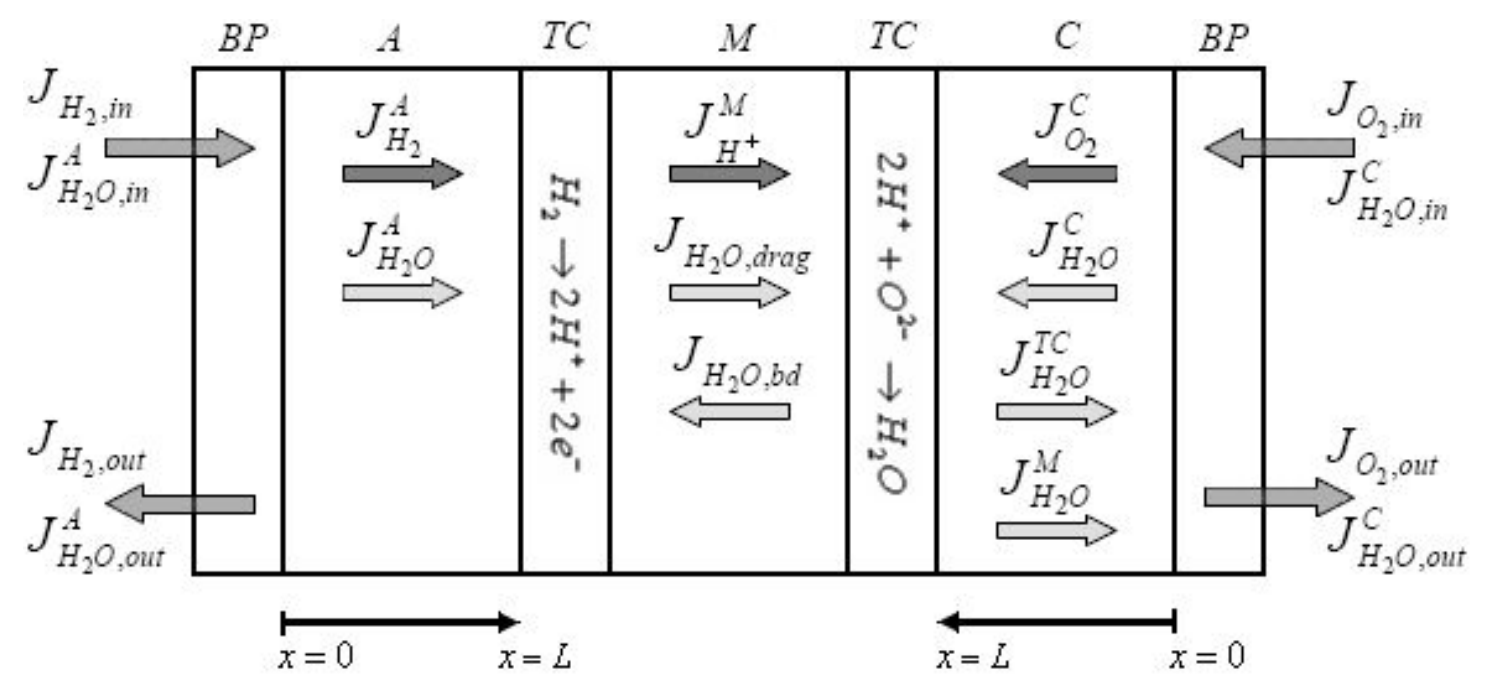

Fig. 2 Gas and water diffusion inside the cell. 
$\left.a_{w}^{C}\right)$. These latter depend on water mole fractions (amount of water vapor) in hydrogen $X_{\mathrm{H}_{2} \mathrm{O}}^{\mathrm{A}}$ and oxygen $\mathrm{X}_{\mathrm{H}_{2} \mathrm{O}}^{\mathrm{C}}$.

According to Ref. [29], the water activity $a_{w}$ is related to water mole fractions $X_{\mathrm{H}_{2} \mathrm{O}}$, input gas pressure $P_{i n}$ and saturated vapor pressure $P_{T_{i n}}^{\text {sat }}$ ( $T_{i n}$ is the gas input temperature):

$$
a_{w}=X_{H_{2} O} \frac{P_{i n}}{P_{T_{i n}}^{s a t}},
$$

with

$$
P_{T_{\text {in }}}^{\text {sat }}=10^{\left(-2.17+29 \times 10^{-5} T_{\text {in }}-9.18 \times 10^{-5} T_{\text {in }}^{2}+1.44 \times 10^{-7} T_{\text {in }}^{3}\right)} \text {. }
$$

We emphasis that a detailed description of sorption and desorption mechanisms inside the membrane is extremely difficult because it depends widely on the characteristics of the electrolyte (Nafion) which is a complicated composition of fluor, ethylene and sulfuric acid. However, experimental works provide the evolution of $\lambda$ with respect to $a_{w}$ [29] (see Fig. 3).

At normal operating conditions, $\lambda$ is between 2 and 14 in order to avoid drying $(\lambda<2)$ or fully humidified $(\lambda>14)$ effects. Since the operating temperature of PEM fuel cells is $T=80^{\circ} \mathrm{C}$, the expression of $\lambda$ with respect to $a_{w}$ (resulting from Fig. 3) is given by:

$$
\lambda=a_{1}+a_{2} a_{w}-a_{3} a_{w}^{2}+a_{4} a_{w}^{3}
$$

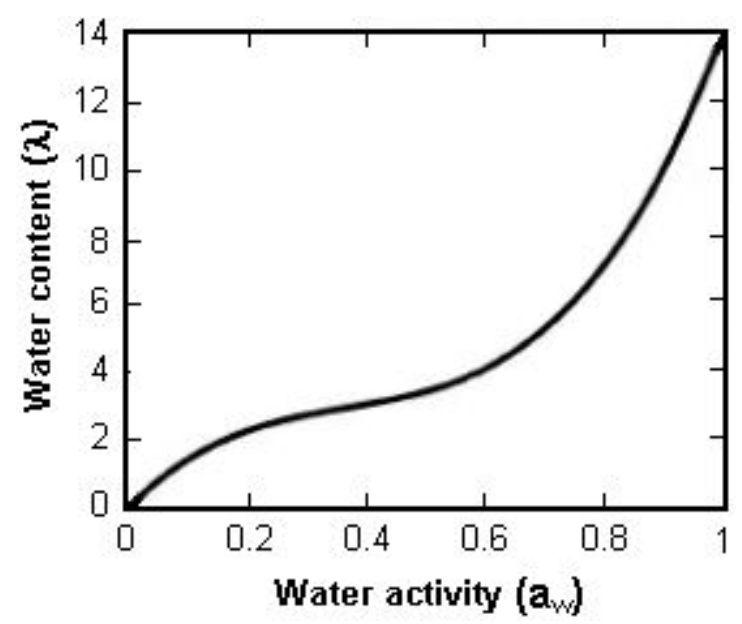

Fig. 3 Membrane water content with respect to water activity.
With $\quad a_{1}=0.3 ; a_{2}=10.8 ; a_{3}=16 ; a_{4}=14$

Because the membrane thickness is very small, we consider the mean water content $\lambda_{m}$ calculated from boundary conditions at anode side $\lambda^{A}$ and cathode side $\lambda^{C}$ :

$$
\begin{aligned}
& \lambda^{A}=a_{1}+a_{2} a_{w}^{A}-a_{3}\left(a_{w}^{A}\right)^{2}+a_{4}\left(a_{w}^{A}\right)^{3} ; \\
& \lambda^{C}=a_{1}+a_{2} a_{w}^{C}-a_{3}\left(a_{w}^{C}\right)^{2}+a_{4}\left(a_{w}^{C}\right)^{3} .
\end{aligned}
$$

Consequently, $\lambda_{m}$ is:

$$
\begin{aligned}
& \lambda_{m}=\frac{\lambda^{A}+\lambda^{C}}{2}=a_{1}+\frac{a_{2}}{2}\left[a_{w}^{A}+a_{w}^{C}\right] \\
& -\frac{a_{3}}{2}\left[\left(a_{w}^{A}\right)^{2}+\left(a_{w}^{C}\right)^{2}\right]+\frac{a_{4}}{2}\left[\left(a_{w}^{A}\right)^{3}+\left(a_{w}^{C}\right)^{3}\right]
\end{aligned}
$$

Now, according to Eq. (21) the anode and cathode water activities $\left(a_{w}^{A}, a_{w}^{C}\right)$ are:

$$
\begin{aligned}
& a_{w}^{A}=X_{H_{2} O}^{A} \frac{P_{a n, i n}}{P_{T_{a n, i n} s t}^{s a t}}=X_{H_{2} O}^{A} \frac{P_{H_{2}}^{B P}}{P_{T_{a n, i n} s a}^{s}} ; \\
& a_{w}^{C}=X_{H_{2} O}^{C} \frac{P_{c a, i n}}{P_{T_{c a, i n}}^{s a t}}=X_{H_{2} O}^{C} \frac{P_{O_{2}}^{B P}}{P_{T_{c a, i n}}^{s a t}} .
\end{aligned}
$$

Given that $J_{H_{2}}^{B P}=2 J_{\mathrm{O}_{2}}^{B P}$, according to Eq. (13), we have:

$$
\begin{aligned}
& P_{H_{2}}^{B P}=\frac{R_{g} T L}{A D_{H_{2}}} J_{H_{2}}^{B P}+P_{H_{2}}^{T C} ; \\
& P_{O_{2}}^{B P}=\frac{R_{g} T L}{A D_{O_{2}}} \frac{J_{H_{2}}^{B P}}{2}+P_{O_{2}}^{T C} .
\end{aligned}
$$

Hence, Eq. (25) becomes:

$$
\begin{aligned}
& a_{w}^{A}=\frac{R_{g} T L_{a} J_{H_{2}}^{B P}+D_{H_{2}} P_{H_{2}}^{T C}}{D_{H_{2}} P_{T_{a n, i n}}^{s a t}} X_{H_{2} O}^{A} O \\
& a_{w}^{C}=\frac{R_{g} T L_{c} J_{H_{2}}^{B P}+2 D_{O_{2}} P_{O_{2}}^{T C}}{2 D_{O_{2}} P_{T_{c a, i n}}^{s a t}} X_{H_{2} O}^{C} .
\end{aligned}
$$

\subsection{Electrical Process}

Since the fuel cell is an electrical power source system, representing it as an electrical circuit is quite useful. Indeed, the electrochemical phenomena produced 
inside the fuel cell components are modeled by electric impedances. The so-called inherent impedance is the equivalent circuit of these components that represents the losses. It is composed of:

Three types of resistances representing ohmic losses $\left(R_{m}, R_{a}\right.$ and $\left.R_{c}\right)$, activation losses $\left(R_{a c t}^{a}\right.$ and $\left.R_{a c t}^{c}\right)$ and concentration losses ( $R_{\text {conc }}^{a}$ and $R_{\text {conc }}^{c}$ ). $R_{a}$ and $R_{c}$ represent the total ohmic resistances of the bipolar plates, the diffusion layers and the electrodes at anode and cathode sides. The membrane's resistance $R_{m}$ depends on its physical structure, humidity and temperature.

Two charge capacities $C_{d l}^{a}$ and $C_{d l}^{c}$ are due to the double layer phenomenon between the electrodes (anode or cathode) and the electrolyte (membrane). Indeed, the structure of charge accumulation and the charge separation always occur at the interface when an electrode is immersed into an electrolyte solution. The excess charge on the electrode surface is compensated by an accumulation of excess ions of the opposite charge in the solution. This structure behaves essentially as capacitor.

One geometrical capacity $C_{\text {geom }}$ between the electrodes. It follows from the fact that two electrodes (anode, cathode) separated with an isolator (electrolyte) produce a capacitance effect between them.

Including the electrochemical reaction potential and the load resistance into the inherent impedance we obtain a complete equivalent circuit of the cell (Fig. 4). In Fig. $4, i_{t}$ is the total current, $i_{c}$ is the geometrical capacity current, $i$ is the output current and $R_{0}=R_{a}+R_{c}+R_{m}$ is the ohmic resistance. The membrane resistance $R_{m}$ depends on its electrical conductivity $\sigma_{\lambda_{m}, T}$, its surface $A$ and its thickness $L_{m}$ [30]:

$$
R_{m}=\frac{L_{m}}{A \sigma_{\lambda_{m}, T}}=\frac{L_{m}}{A\left(a_{5} \lambda_{m}-a_{6}\right)}
$$

with $\quad a_{5}=5139 \times 10^{-6} \exp \left[1268\left(\frac{1}{303}-\frac{1}{T}\right)\right] \quad$ and $a_{6}=326 \times 10^{-5} \exp \left[1268\left(\frac{1}{303}-\frac{1}{T}\right)\right] . \quad$ The model shown in Fig. 4 is an integral circuit that appears to be more realistic by introducing activation, ohmic and concentration losses as well as the double layer and geometrical capacitance effects.

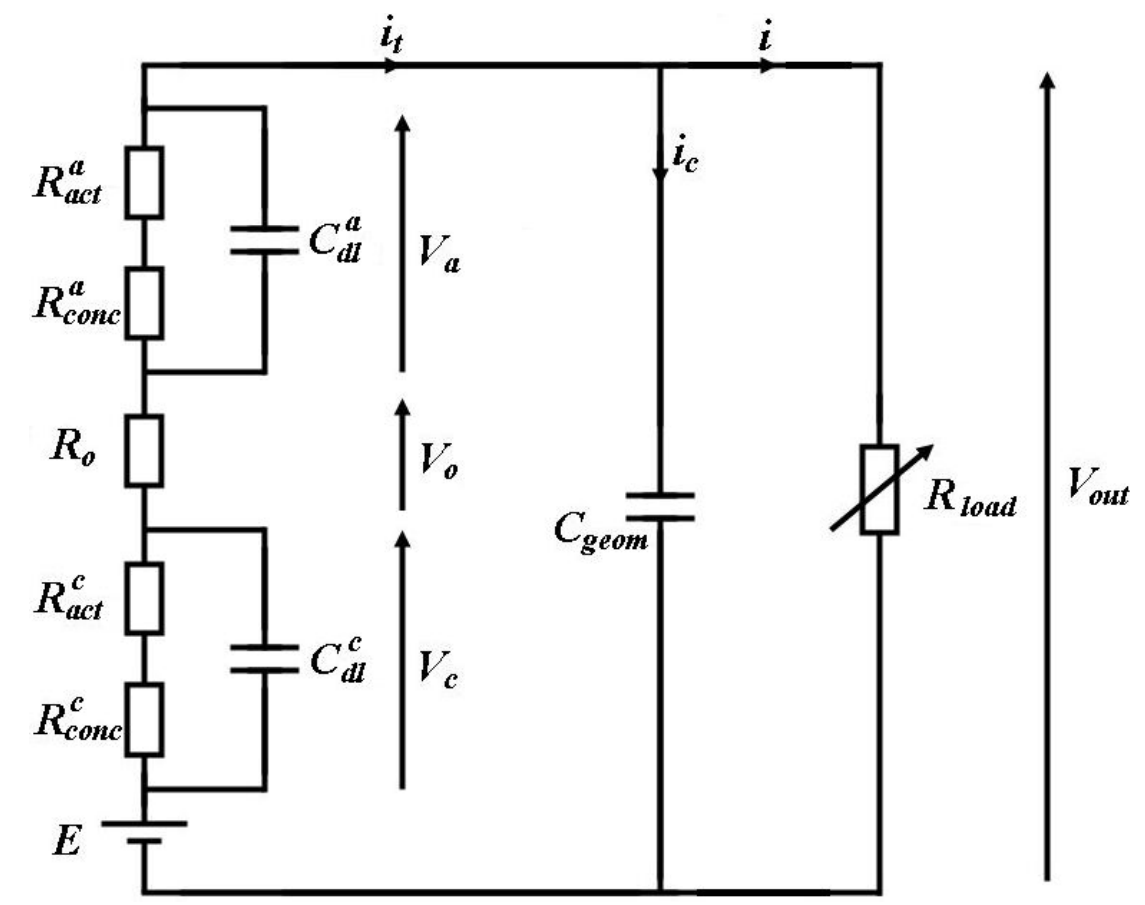

Fig. 4 Equivalent circuit of one cell. 
According to Eq. (2) the electrochemical potential $E$ with respect to internal pressures $P^{T C}$ is:

$$
E=E^{0}+\frac{R_{g} T}{2 F} \operatorname{In}\left(\frac{P_{H_{2}}^{T C} \sqrt{P_{O_{2}}^{T C}}}{P_{H_{2} O}^{T C}}\right)
$$

Let $V_{e}$ be either $V_{a}$ or $V_{c}$, according to Ohm's law, the expression of $V_{e}$ from the equivalent circuit is as follows:

$$
V_{e}=-\left(R_{a c t}+R_{c o n c}\right)\left[i_{t}+C_{d l} \frac{d V_{e}}{d t}\right]
$$

where,

$$
\begin{aligned}
& R_{a c t}=\frac{R_{g} T}{2 \alpha F i_{t}} \operatorname{In}\left(\frac{i_{t}}{i_{o}}\right) ; \\
& R_{\text {conc }}=\frac{R_{g} T}{2 \alpha F i_{t}} \operatorname{In}\left(1-\frac{i_{t}}{i_{l}}\right) ; \\
& i_{t}=2 F J_{H_{2}}^{B P}=4 F J_{O_{2}}^{B P}=2 F J_{H_{2} O}^{B P} .
\end{aligned}
$$

It follows that:

$$
\frac{d V_{e}}{d t}=-\frac{a_{7} J_{H_{2}}^{B P} V_{e}}{\operatorname{In}\left(a_{8} J_{H_{2}}^{B P}-a_{9} J_{H_{2}}^{B P^{2}}\right)}-a_{10} J_{H_{2}}^{B P}
$$

with $\quad a_{7}=\frac{4 \alpha F^{2}}{R_{g} T C_{d l}}, a_{8}=\frac{2 F}{i_{0}}, a_{9}=\frac{4 F^{2}}{i_{0} i_{t}}$, and $a_{10}=\frac{2 F}{C_{d l}}$.

Now, the ohmic voltage $V_{o}$ is given by:

$$
V_{o}=-i_{t} R_{o}=-2 F J_{H_{2}}^{B P}\left[R_{a}+R_{c}+\frac{L_{m}}{A\left(a_{5} \lambda_{m}-a_{6}\right)}\right]
$$

Hence, the output voltage $V_{\text {out }}$ becomes:

$$
\begin{aligned}
& V_{\text {out }}=E+2 V_{e}+V_{o}=E^{0}+\frac{R_{g} T}{2 F} \operatorname{In}\left(\frac{P_{H_{2}}^{T C} \sqrt{P_{O_{2}}^{T C}}}{P_{H_{2} O}^{T C}}\right) \\
& +2 V_{e}-2 F J_{H_{2}}^{B P}\left[R_{a}+R_{c}+\frac{L_{m}}{A\left(a_{5} \lambda_{m}-a_{6}\right)}\right]
\end{aligned}
$$

According to the electrical circuit, $i=i_{t}-i_{c}$ with
$i_{c}=C_{\text {geom }} \frac{d v_{\text {out }}}{d t}$. Consequently, the output current becomes:

$$
\begin{aligned}
& i=2 F J_{H_{2}}^{B P}\left[1-\frac{L_{m} C_{\text {geom }} a_{5}}{A\left(a_{5} \lambda_{m}-a_{6}\right)^{2}} \frac{d \lambda_{m}}{d t}\right]-2 C_{\text {geom }} \frac{d V_{e}}{d t} \\
& -2 F C_{\text {geom }} \frac{d J_{H_{2}}^{B P}}{d t}\left[R_{a}+R_{c}+\frac{L_{m}}{A\left(a_{5} \lambda_{m}-a_{6}\right)}\right] \\
& -\frac{R_{g} T C_{\text {geom }}}{2 F}\left[\frac{\dot{P}_{H_{2}}^{T C}}{P_{H_{2}}^{T C}}+\frac{\dot{P}_{O_{2}}^{T C}}{2 P_{O_{2}}^{T C}}-\frac{\dot{P}_{H_{2} O}^{T C}}{P_{H_{2} O}^{T C}}\right]
\end{aligned}
$$

Finally, the expressions of the total, useful and lost powers $\left(P_{t}, P_{u}\right.$ and $\left.P_{p}\right)$ are:

$$
\begin{aligned}
& P_{t}=E \times i ; \\
& P_{u}=V_{\text {out }} \times i ; \\
& P_{p}=P_{t}-P_{u} .
\end{aligned}
$$

\subsection{State-Space Model}

In this part, we present the global state-space model based on diffusional, water transport and electrical processes. First, we emphasis that Eqs. (18)-(20) and (34) show that internal diffusion flows $J^{T C}$ and the output current $i$ depend on input derivatives $\left(\dot{u}_{1}, \dot{u}_{4}, \dot{u}_{5}\right.$ and $\left.\dot{u}_{6}\right)$. This fact is generally negative because the derivative mode can amplify the outputs noise. Therefore, we use a low-pass filter to eliminate the noise increasing in derivative mode. Consequently, the first order derivative of the input variables can be approximated by the following equation [31]:

$$
s U(s) \approx K\left(1-\frac{1}{1+s / K}\right) U(s)
$$

where $K$ is an approximation factor greater than 10 . Let $v$ be an auxiliary input defined as $v(s)=\frac{K}{1+s / K} U(s)$. Then we have:

$$
\begin{aligned}
& \dot{u}=K u-v ; \\
& \dot{v}=K^{2} u-K v .
\end{aligned}
$$

We define $\left[v_{1} \cdots v_{6}\right]$ as intermediate variables related to $\left[\dot{u}_{1} \cdots \dot{u}_{6}\right]$ and we introduce them to the 
model. Hence, we define the state-space vector as follows:

$$
x=\left[J_{H_{2}}^{T C}, J_{O_{2}}^{T C}, J_{H_{2} O}^{T C}, V_{e}, v_{1}, v_{2}, v_{3}, v_{4}, v_{5}, v_{6}\right]^{T}
$$

This together with all the above equations leads to the global state-space model:

$$
\begin{aligned}
& \dot{x}_{1}=\alpha_{2} x_{1}-\alpha_{2} u_{1}+\alpha_{1}\left(K u_{4}-x_{8}\right) ; \\
& \dot{x}_{2}=\beta_{3} x_{2}-\beta_{2} u_{1}+\beta_{1}\left(K u_{5}-x_{9}\right) ; \\
& \dot{x}_{3}=\gamma_{2} x_{3}-\gamma_{2} u_{1}+\gamma_{1}\left(K u_{6}-x_{10}\right) ; \\
& \dot{x}_{4}=-\frac{a_{7} u_{1} x_{4}}{\operatorname{In}\left(a_{8} u_{1}-a_{9} u_{1}^{2}\right)}-a_{10} u_{1} ; \\
& \dot{x}_{5}=K^{2} u_{1}-K x_{5} ; \quad \dot{x}_{6}=K^{2} u_{2}-K x_{6} ; \\
& \dot{x}_{7}=K^{2} u_{3}-K x_{7} ; \quad \dot{x}_{8}=K^{2} u_{4}-K x_{8} ; \\
& \dot{x}_{9}=K^{2} u_{5}-K x_{9} ; \quad \dot{x}_{10}=K^{2} u_{6}-K x_{10} ; \\
& y_{1}=E^{0}+\frac{R_{g} T}{2 F} \operatorname{In}\left[\frac{P_{H_{2}}^{T C} \sqrt{P_{O_{2}}^{T C}}}{P_{H_{2} O}^{T C}}\right]+2 x_{4} \\
& -2 F u_{1}\left(R_{a}+R_{c}+\frac{L_{m}}{A\left(a_{5} \lambda_{m}-a_{6}\right)}\right) \text {; } \\
& y_{2}=2 F u_{1}\left[1-\frac{L_{m} C_{\text {geom }} a_{5}}{A\left(a_{5} \lambda_{m}-a_{6}\right) 2} \frac{d \lambda_{m}}{d t}\right]-2 C_{\text {geom }} \dot{x}_{4} \\
& -2 F C_{\text {geom }}\left(K u_{1}-x_{5}\right)\left[R_{a}+R_{c}+\frac{L_{m}}{A\left(a_{5} \lambda_{m}-a_{6}\right)}\right] \\
& -\frac{R_{g} T C_{\text {geom }}}{2 F}\left[\frac{\dot{P}_{H_{2}}^{T C}}{P_{H_{2}}^{T C}}+\frac{\dot{P}_{O_{2}}^{T C}}{2 P_{O_{2}}^{T C}}-\frac{\dot{P}_{H_{2} \mathrm{O}}^{T C}}{P_{H_{2} \mathrm{O}}^{T C}}\right] .
\end{aligned}
$$

where,

$$
\begin{aligned}
& \lambda_{m}=a_{1}+M_{1} u_{2}\left[\frac{a_{2}}{2}-\frac{M_{1} a_{3} u_{2}}{2}+\frac{M_{1}^{2} a_{4} u_{2}^{2}}{2}\right] \\
& +M_{2} u_{3}\left[\frac{a_{2}}{2}-\frac{M_{2} a_{3} u_{3}}{2}+\frac{M_{2}^{2} a_{4} u_{3}^{2}}{2}\right]
\end{aligned}
$$

$$
\begin{gathered}
\frac{d \lambda_{m}}{d t}=\left[M_{1} \dot{u}_{2}+M_{3} u_{2}\right]\left[\frac{a_{2}}{2}-\frac{M_{1} a_{3} u_{2}}{2}+\frac{M_{1}^{2} a_{4} u_{2}^{2}}{2}\right] \\
+\left[M_{2} \dot{u}_{3}+M_{4} u_{3}\right]\left[\frac{a_{2}}{2}-\frac{M_{2} a_{3} u_{3}}{2}+\frac{\left.M_{2}^{2} a_{4} u_{3}^{2}\right]}{2}\right] \\
+M_{1} u_{2}\left[-\frac{M_{1} a_{3} \dot{u}_{2}}{2}-\frac{M_{3} a_{3} u_{2}}{2}+M_{1}^{2} a_{4} \dot{u}_{2}+M_{1} M_{3} a_{4} u_{2}^{2}\right] \\
+M_{2} u_{3}\left[-\frac{M_{2} a_{3} \dot{u}_{3}}{2}-\frac{M_{4} a_{3} u_{3}}{2}+M_{2}^{2} a_{4} \dot{u}_{3}+M_{2} M_{4} a_{4} u_{3}^{2}\right] \\
\dot{u}_{1}=K u_{1}-x_{5} ; \quad \dot{u}_{2}=K u_{2}-x_{6} ; \\
\dot{u}_{3}=K u_{3}-x_{7} ; \quad \dot{u}_{4}=K u_{4}-x_{8} ; \\
\dot{u}_{5}=K u_{5}-x_{9} ; \quad \dot{u}_{6}=K u_{6}-x_{10} ; \\
P_{H_{2}}^{T C}=u_{4}-\alpha_{3} u_{1} ; \quad P_{O_{2}}^{T C}=u_{5}-\beta_{4} u_{1} ; \\
M_{H_{2} O}^{T C}=\frac{u_{6}-\gamma_{3} u_{1} ;}{D_{H_{2}} P_{T_{a n, i n}}^{s a t}}+\frac{\dot{x}_{1}}{P_{T_{a n, i n}}^{s a t}} ; \quad M_{4}=\frac{R_{g} T L_{c} \dot{u}_{1}}{2 D_{O_{2}} P_{T_{c a, i n}}^{s a t}}+\frac{\dot{x}_{2}}{P_{T_{c a, j i n}}^{s a t}} . \\
M_{1}=\frac{R_{g} T L_{a} u_{1}}{D_{H_{2}} P_{T_{a n, i n}}^{s a t}}+\frac{P_{H_{2}}^{T C}}{P_{T_{a n, i n}}^{s a t}} ; \quad M_{2}=\frac{R_{g} T L_{c} u_{1}}{2 D_{O_{2}} P_{T_{c a, i n}}^{s a t}}+\frac{P_{O_{2}}^{T C}}{P_{T_{c a, i n}}^{s a t}} ; \\
R_{a} L_{u_{1}}
\end{gathered}
$$

\section{Simulation and Results}

As mentioned before, the objective of the modeling is to study the effect of water management on the system's performance. The results can be used in a future work to build an appropriate control for humidity minimizing power loss. This can be done by studying the effect of water mole fractions on both membrane's humidity and electrical outputs. Simulation parameters are drawn from the works of Refs. [29, 30, 32].

To deal with humidity control in dynamical behavior (case of transportation applications), first we need to understand the effect of water mole fractions for a static power demand, i.e., $J_{H_{2}}^{A}=J_{H_{2}}^{B P}=c s t$. First of all, we state constraints ensuring system 
stability. Indeed, the current density is stated between the exchange and the limit current densities $\left(j_{0}<j<j_{l}\right)$. It is important to note that the limiting current is a specific value dependent of the cell design and the material properties.

Now, constraints are $J_{H_{2} \min }^{A}=\frac{j_{0}}{2 F} \quad$ and $J_{H_{2} \max }^{A}=\frac{j_{l}}{2 F}$ (see Eq. (4)). Besides, the membrane humidity must be $2<\lambda_{m}<14$ in order to avoid risk of membrane dry-out or flooding. Under these constraints, we simulate in Fig. 5 the effect of $X_{\mathrm{H}_{2} \mathrm{O}}^{A}$ for constant values of $X_{\mathrm{H}_{2} \mathrm{O}}^{\mathrm{C}}$. We apply a sinusoidal variation of $\mathrm{X}_{\mathrm{H}_{2} \mathrm{O}}^{\mathrm{A}}$ between 0 and 1.15 (Fig. 5a) corresponding to a variation between $0 \%$ and $100 \%$ of $a_{w}^{A}$ (Fig. 5b). For such a variation, $X_{\mathrm{H}_{2} \mathrm{O}}^{C} \geq 0.27$ and $\lambda_{m}>2$.

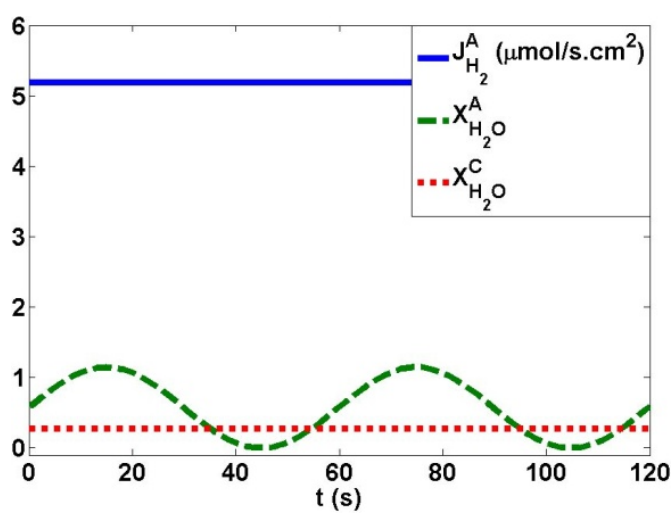

(a)

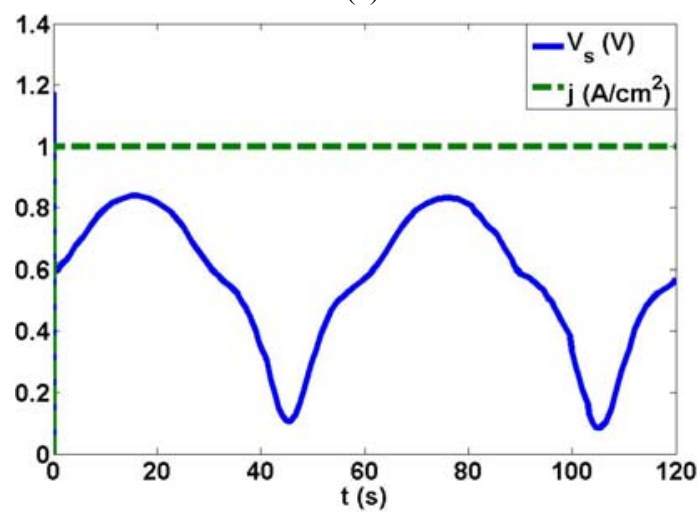

(c)
Fig. $5 \mathrm{~b}$ shows that $\lambda_{m}$ behaves similarly to $a_{w}^{A}$. Figs. 5c and 5d) show that $V_{\text {out }}$ and $P_{u}$ behave similarly to $\lambda_{m}$ while $P_{p}$ behaves conversely to it. This is in agreement with membrane operating principle. Indeed, the more the membrane is wet the more its electrical resistance and corresponding ohmic loss are low, and vice versa. However the current density $j$ and the total electrical power $P_{t}$ are constant because the power demand is static $\left(J_{H_{2}}^{A}=\right.$ constant $)$.

Similarly, we simulate in Fig. 6 the effect of $X_{\mathrm{H}_{2} \mathrm{O}}^{\mathrm{C}}$ for constant value of $X_{\mathrm{H}_{2} \mathrm{O}}^{\mathrm{O}}$. A sinusoidal variation of $X_{\mathrm{H}_{2} \mathrm{O}}^{\mathrm{C}}$ between 0.05 and 0.45 is applied in input (Fig. 6a). It corresponds to a variation between $11 \%$ and $97 \%$ of $a_{w}^{C}$ (Fig. 6b). For such a variation, $X_{\mathrm{H}_{2} \mathrm{O}}^{A} \geq 0.42$ and $\lambda_{m}>2$. In this case simulation

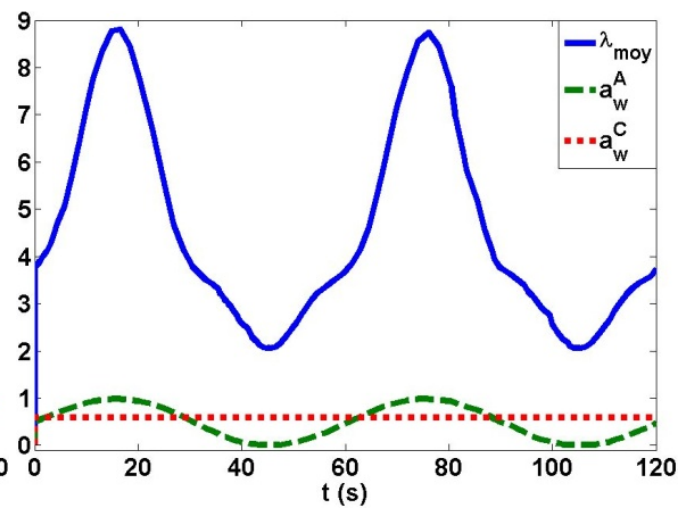

(b)

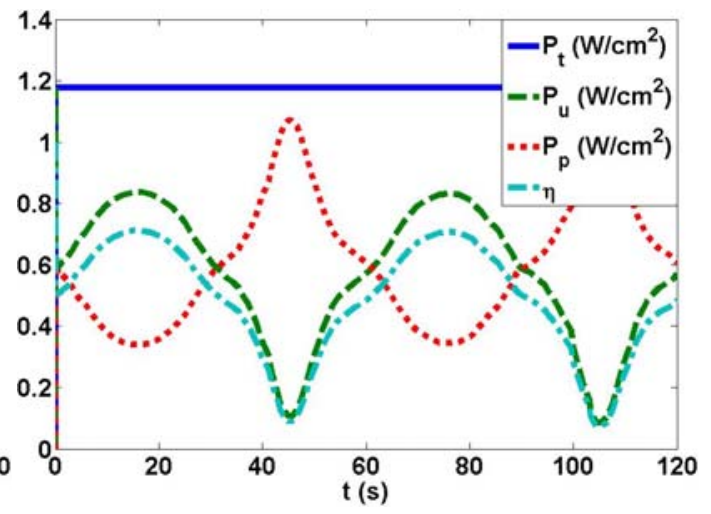

(d)

Fig. 5 Effect of water mole fraction in hydrogen. 


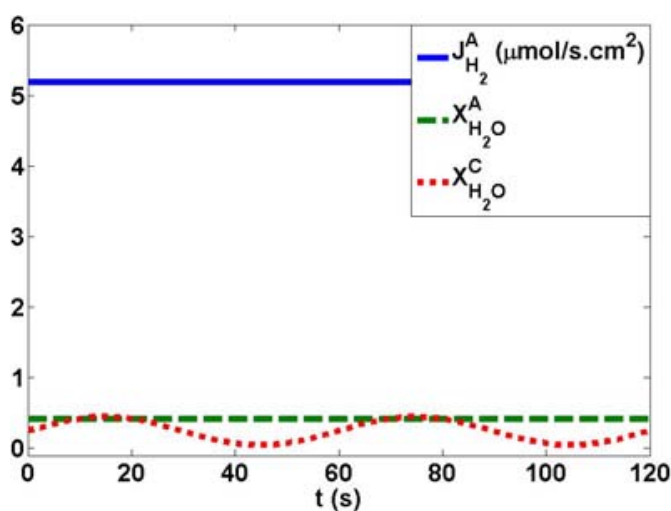

(a)

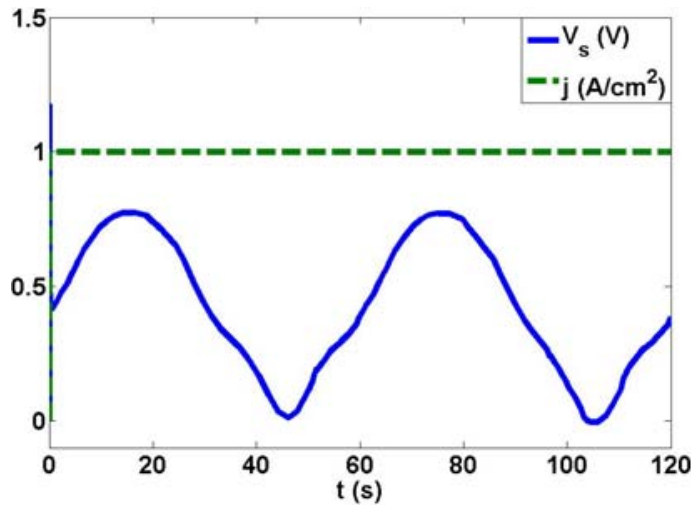

(c)

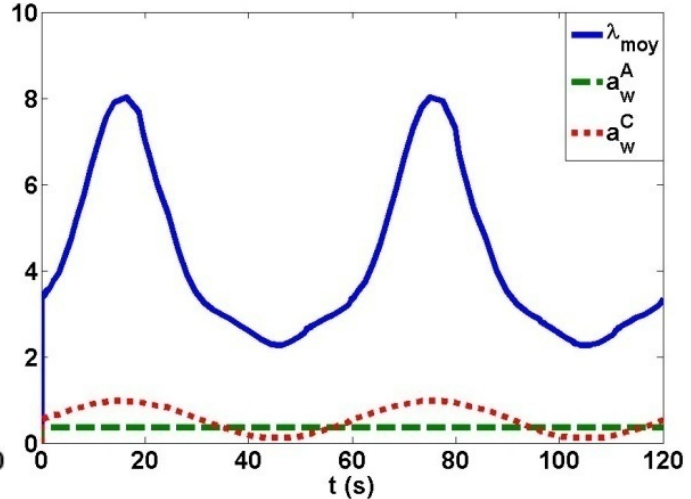

(b)

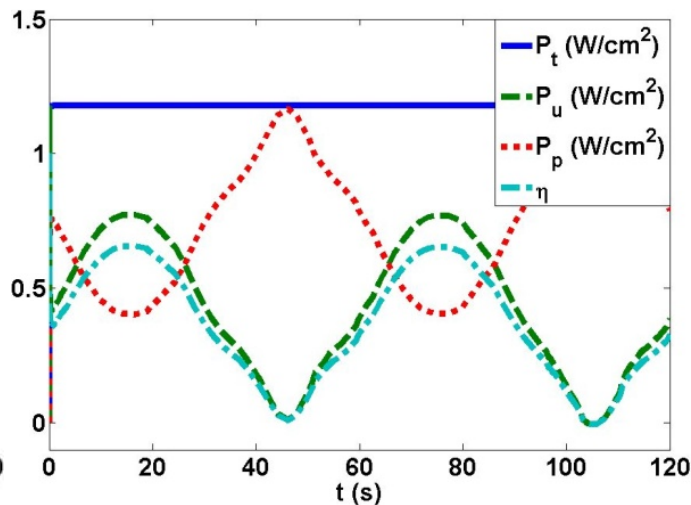

(d)

Fig. 6 Effect of water mole fraction in oxygen.

results mimic the ones of Fig. 5. However, the average values of $\lambda_{m}, V_{\text {out }}$ and $P_{u}$ decreased. Hence, we emphasize that system behavior is more sensitive to $X_{\mathrm{H}_{2} \mathrm{O}}^{\mathrm{A}}$ variation than $X_{\mathrm{H}_{2} \mathrm{O}}^{\mathrm{C}}$ one. This is due to the water production in the cathode side.

In the following, we simulate the effect of $X_{\mathrm{H}_{2} \mathrm{O}}^{\mathrm{A}}$ and $X_{\mathrm{H}_{2} \mathrm{O}}^{\mathrm{C}}$ variations and we study the influence of time phasing between these two inputs. In Fig. 7, we apply at the input a sinusoidal evolution for both $X_{\mathrm{H}_{2} \mathrm{O}}^{\mathrm{A}}$ and $X_{\mathrm{H}_{2} \mathrm{O}}^{\mathrm{C}}$ with a time phasing $\phi=0$ between them. We define the boundaries of these two inputs as follows:

$$
\begin{aligned}
& 0.27<X_{\mathrm{H}_{2} \mathrm{O}}^{A}<0.87 \rightarrow 23 \%<a_{w}^{A}<75 \% \\
& 0.05<X_{\mathrm{H}_{2} \mathrm{O}}^{C}<0.45 \rightarrow 11 \%<a_{w}^{C}<97 \%
\end{aligned}
$$

Simulation results show that effects of $X_{\mathrm{H}_{2} \mathrm{O}}^{\mathrm{A}}$ and $X_{\mathrm{H}_{2} \mathrm{O}}^{\mathrm{C}}$ are added up since there is no time phasing between them. This fact is observed through the outputs which have similar behaviors as before.

Now, we simulate in Fig. 8 the effect of $X_{\mathrm{H}_{2} \mathrm{O}}^{\mathrm{A}}$ and $X_{\mathrm{H}_{2} \mathrm{O}}^{\mathrm{C}}$ variations with a time phasing $\phi=\pi$ between them. In this case, we have:

$$
\begin{aligned}
& 0<X_{H_{2} \mathrm{O}}^{A}<1.15 \rightarrow 0 \%<a_{w}^{A}<100 \% \\
& 0.05<X_{H_{2} O}^{C}<0.45 \rightarrow 11 \%<a_{w}^{C}<97 \%
\end{aligned}
$$

Simulation results show that effects of $X_{\mathrm{H}_{2} \mathrm{O}}^{\mathrm{A}}$ and $X_{\mathrm{H}_{2} \mathrm{O}}^{\mathrm{C}}$ are compensated since the time phasing between them is $\phi=\pi$ (when $X_{\mathrm{H}_{2} \mathrm{O}}^{A}$ is maximum, $X_{\mathrm{H}_{2} \mathrm{O}}^{\mathrm{C}}$ is minimum and vice versa). In this case, output responses do not have similar behaviors as in Fig. 7 in terms of frequencies mean values. In fact, one can observe that the mean value of the efficiency in Fig. $8 \mathrm{~d}\left(\eta_{m} \approx 55 \%\right)$ is better than the one of Fig. $7 \mathrm{~d}\left(\eta_{m} \approx 35 \%\right)$. 


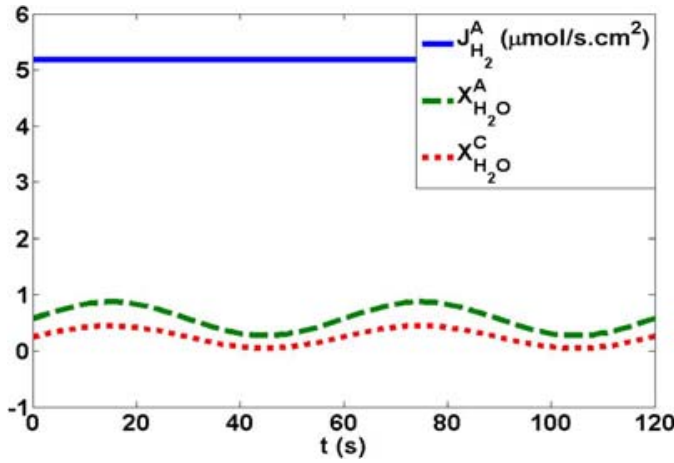

(a)

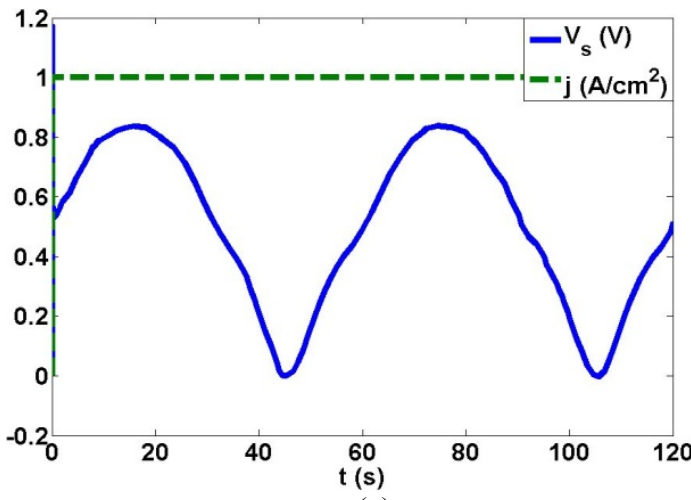

(c)

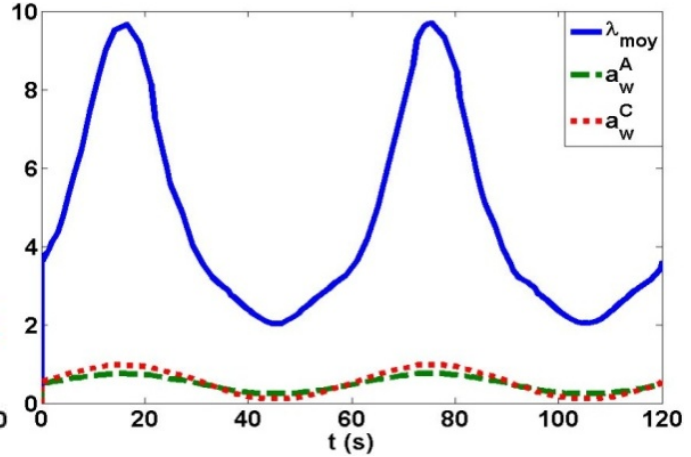

(b)

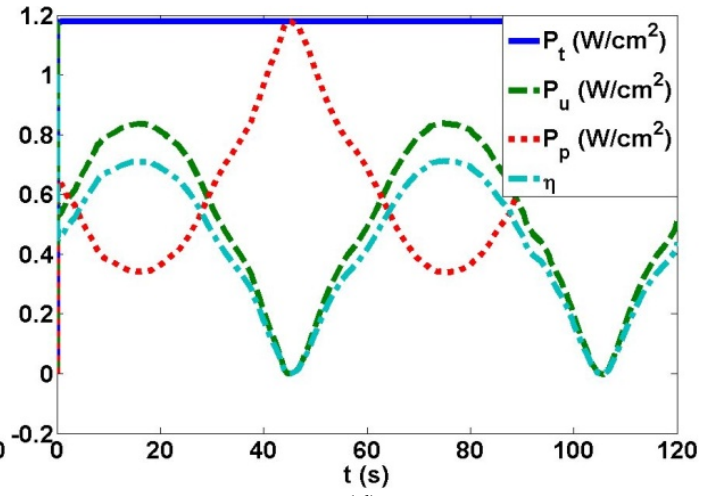

(d)

Fig. 7 Responses to $0^{0}$ phasing between $X_{\mathrm{H}_{2} \mathrm{O}}^{A}$ and $X_{\mathrm{H}_{2} \mathrm{O}}^{\mathrm{C}}$.

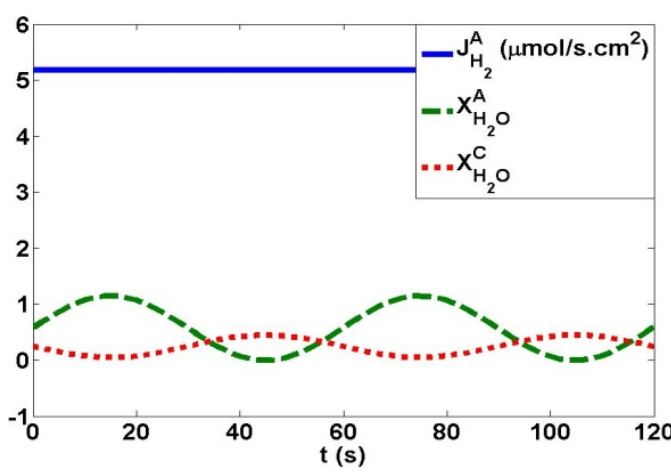

(a)

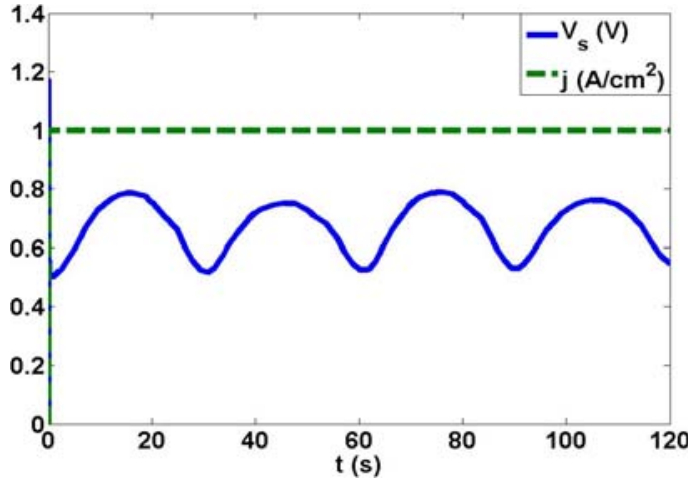

(c)

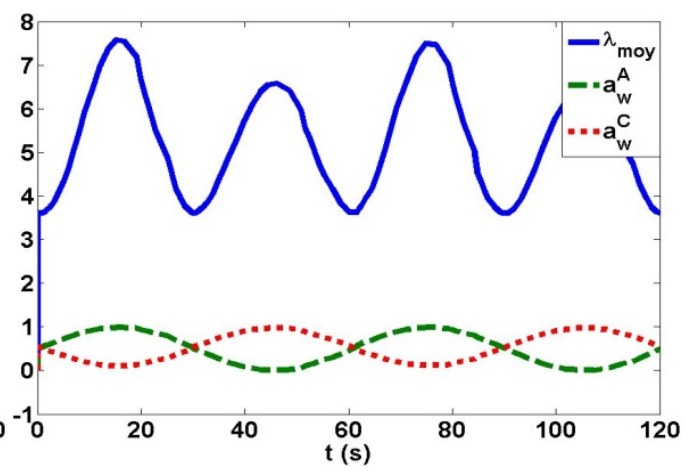

(b)

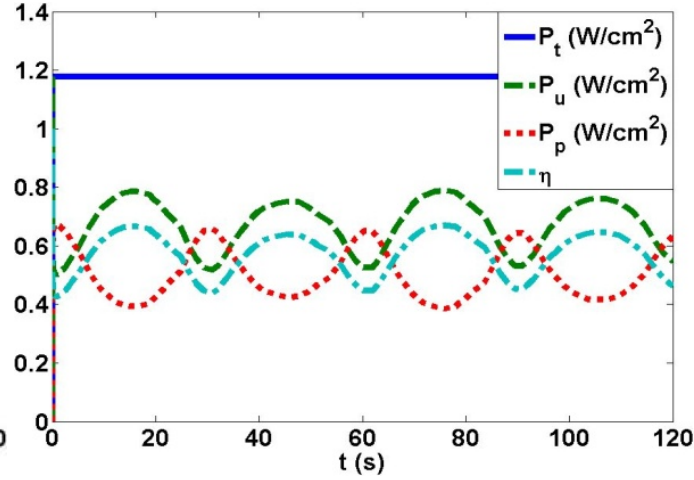

(d)

Fig. 8 Responses to $180^{\circ}$ phasing between $X_{\mathrm{H}_{2} \mathrm{O}}^{A}$ and $X_{\mathrm{H}_{2} \mathrm{O}}^{\mathrm{C}}$. 
In summary, results presented in this part give us qualitative information concerning the effect of the water mole fraction in hydrogen and oxygen as well as their time phasing on the electrical efficiency. These information will be very useful for an appropriate humidification control of the membrane.

\section{Conclusions}

In this paper a control-oriented mathematical modeling of humidity in PEM fuel cells is built. The proposed model is able to calculate the membranes water content thereby solving the problem of placing a humidity sensor inside the cell. This work considers interactions between fuel cell's nonlinear phenomena and proposes a more complete equivalent circuit coupling between gas diffusion, membrane water content, temperature, activation loss, ohmic loss, concentration loss, as well as double layer and geometrical capacitances. Effects of gas humidification rates on electrical outputs are simulated. Simulation shows interesting results regarding efficiency improvement through humidity control. This offers the opportunity to use the model, in a future work, to improve PEM fuel cells efficiency and lifetime.

\section{References}

[1] Kulikovsky, A. A. 2001. "Quasi Three-Dimensional Modeling of the PEM Fuel Cell: Comparison of the Catalyst Layers Performance." Fuel Cells (1): 162-9.

[2] Rowe, A., and Li, X. 2001. "Mathematical Modeling of Proton Exchange Membranefuel Cells." Journal of Power Sources (102): 82-96.

[3] Bradean, R., Promislow, K., and Wetton, B. 2001. "Heat and Mass Transfer in Porousfuel Cell Electrodes." In Proceedings of the International Symposium on Advances in Computational Heat Transfer, 969-76.

[4] Pisani, L., Murgia, G., Valentini, M., and Aguanno, B. D. 2002. "A New Semi-Empirical Approach to Performance Curves of Polymer Electrolyte Fuel Cells." Journal of Power Sources (108): 192-203.

[5] Marr, C., and Li, X. 2004. "An Engineering Model of Proton Exchange Membrane Fuel Cell Performance." ARI (50): 190-200.

[6] Gurau, V., Liu, H., and Kaka, S. 2004. "Separation
Two-Dimensional Model for Proton Exchange Membrane Fuel Cells." American Institute of Chemical Engineers Journal (44): 2410-22.

[7] Moya, A. A. 2012. "Electric Circuits Modelling the Low-Frequency Impedance of Ideal Ion-Exchange Membrane Systems." Electrochimica Acta (62): 296-304.

[8] Saadi, A., Becherif, M., Aboubou, A., and Ayad, M. Y. 2013. "Comparison of Pro-Ton Exchange Membrane Fuel Cell Static Models.” Renewable Energy (56): 64-71.

[9] Lachaize, J. 2004. "Study of Strategiesand Control Structures Fordrivingtraction Fuel Cell's Power Systems." Ph.D. thesis, Laboratory of Electrotechnics and Industrial Electronics, ENSEEIHT, Toulouse.

[10] Caux, S., Lachaize, J., Fadel, M., Shott, P., and Nicod, L. 2005. "Modeling and Control of a Fuel Cell System and Storage Elements in Transport Applications." Journal of Process Control (15): 481-91.

[11] Mueller, F., Brouwer, J., Kang, S., Kim, H., and Min, K. 2007. "Quasi-Three Dimen-Sional Dynamic Model of a Proton Exchange Membrane Fuel Cell for System and Controls Development." Journal of Power Sources (163): 814-29.

[12] Sharifi Asl, S. M., Rowshanzamir, S., and Eikani, M. H. 2010. "Modelling and Simulation of the Steady-State and Dynamic Behaviour of a PEM Fuel Cell." Renewable Energy (35): 1633-46.

[13] Yerramalla, S., Davari, A., Feliachi, A., and Biswas, T. 2003. "Modeling and Simulation of the Dynamic Behavior of a Polymer Electrolyte Membrane Fuel Cell." Journal of Power Sources (124): 104-13.

[14] Pukrushpan, J., Peng, H., and Stefanopoulou, A. 2004. "Control-Oriented Modeling and Analysis for Automotive Fuel Cell Systems." Journal of Dynamic Systems, Measurement and Control (126): 14-25.

[15] Ziogou, C., Voutetakis, S., Papadopoulou, S., and Georgiadis, M. 2010. "Modeling and Experimental Validation of a Pem Fuel Cell System." 20th European Symposium on Computer Aided Process Engineering.

[16] Shen, C., Cao, G. Y., and Zhu, X. J. 2002. "Nonlinear Modeling of MCFC Stack Based on RBF Neural Networks Identification." Simulation Modelling Practice and Theory (10): 109-19.

[17] Shen, C., Cao, G. Y., Zhu, X. J., and Sun, X. J. 2002. "Nonlinear Modeling and Adaptive Fuzzy Control of MCFC Stack." Journal of Process Control (12): 831-39.

[18] Golbert, J., and Lewin, D. 2004. "Model-Based Control of Fuel Cells: Regulatory Control." Journal of Power Sources (135): 135-51.

[19] Shen, C. 2004. "Control-Oriented Nonlinear Modelling of Molten Carbonate Fuel Cells." International Journal of Energy Research (28): 403-10.

[20] Mangold, M., Krasnyk, M., and Sundmacher, K. 2004. 
"Nonlinear Analysis of Current Instabilities in High Temperature Fuel Cells." Chemical Engineering Science (59): 4869-77.

[21] Sun, T., Cao, G., and Zhu, X. 2005. "Nonlinear Modeling of PEMFC Based on Neural Networks Identification." Journal of Zhejiang University Science A (6): 365-70.

[22] Qi, Y., Huang, B., and Chuang, K. 2005. "Dynamic Modeling of Solid Oxide Fuel Cell: The EECT of Diffusion and Inherent Impedance." Journal of Power Sources (150): 32-47.

[23] Shokuhi-Rad, A., Jamali, A., Naghashzadegan, M., Nariman-zadeh, N., and Hajiloo, A. 2012. "Optimum Pareto Design of Non-linear Predictive Control with Multi-design Variables for PEM Fuel Cell.” International Journal of Hydrogen Energy (37): 11244-54.

[24] Wang, Y., and Wang, C. 2005. "Transient Analysis of Polymer Electrolyte Fuel Cells." Electrochemica Acta (50): 1307-15.

[25] Wang, Y., and Wang, C. 2007. "Two Phase Transients of Polymer Electrolyte Fuel Cells." Journal of The Electrochemical Society (154): 636-43.

[26] Fuller, T., and Newman, J. 1992. "Experimental
Determination of the Transport Number of Water in Nafion 117 Membrane." Journal of The Electrochemical Society (139): 1332-7.

[27] Okada, T., Xie, G., and Tanabe, Y. 1996. "Theory of Water Management at the Anode Side of Polymer Electrolyte Fuel Cell Membranes." Journal of Electroanalytical Chemistry (413): 49-65.

[28] Campanari, S., and Iora, P. 2004. "Definition Sensitivity Analysis of a Fnite Volume SOFC Model for a Tubular Cell Geometry." Journal of Power Sources (132): 113-26.

[29] Hayre, R. O, Cha, S., Colella, W., and Prinz, F. 2009. Fuel Cell Fundamentals. 2nd Edition, New York: John Wiley and Sons.

[30] Saisset, R. 2004. "Contribution to the Systemic Study of Energetic Devices for Electrochemical Components." $\mathrm{Ph} . \mathrm{D}$. thesis, Laboratory of Electrotechnics and Industrial Electronics, ENSEEIHT, Toulouse.

[31] Seborg, D. E., Edgar, T. F., and Mellichamp, D. A. 1989. Process Dynamics and Control. John Wiley and Sons, Inc.

[32] Barbir, F. 2012. PEM Fuel Cells. 2nd Edition, Elsevier, Oxford. 